\title{
ВОЗМОЖНОСТИ ИСПОЛЬЗОВАНИЯ АМАРАНТА В ТЕХНОЛОГИИ ЗЕРНОВЫХ КИСЕЛЕЙ
}

\author{
А. В. Снегирева, Л. Е. Мелёшкина
}

\begin{abstract}
Разработка продуктов питания из растительного сырья, богатого незаменимыми нутриентами была и остается актуальной задачей пищевой промышленности. В связи с чем в данной работе проведено исследование перспектив использования различных видов ячменной муки как сырья для производства киселей и возможности повышения пищевой ценности блюда за счет внесения отрубей амаранта. Определены кислотность, крупность, зольность разных видов ячменной муки. Исследована вязкость клейстеров из ячменной муки разных производителей, подвергнутой термической обработке. Выбран образец с оптимальными технологическими характеристиками, альтернативными картофрельному и кукурузному крахмалу в составе сладкого блюда. Исследована возможность внесения отрубей амаранта в рецептуру киселя и проведен сравнительный анализ пищевой ценности традиционного киселя и киселя на основе ячменной муки с отрубями амаранта. Выявлено положительное влияние отрубей амаранта в составе ячменного киселя на его пищевую ценность. Установлено, что внесение отрубей амаранта и ячменной муки обогащает кисель пищевыми волокнами. Значительно возрастает содержание минеральных веществ, в частности фосфоро, железа, магния и кальция, витаминов $B_{1}$ и $B_{2}$.

Ключевые слова: желированные сладкие блюда, кисель, ячменная мука, отруби амаранта, пищевая ценность, сквален, функциональный, пищевые волокна, атеросклероз, витамины группы $B$.
\end{abstract}

В последние годы в связи с развитием информационных технологий все больше снижается фризическая активность человечества. Весте с тем из-за сильной занятости растет число людей, прибегающих к употреблению «фастфуда», лишенного необходимых витаминов, минеральных веществ, пищевых волокон, при этом содержащего в большом количестве легкоусвояемые углеводы $и$ насыщенные жиры. Намеченная тенденция приводит к истощению инсулярного аппарата, способствует развитию сахарного диабета, ожирения, увеличивает риск сердечнососудистых заболеваний, снижает иммунитет.

В связи с чем актуальной задачей и по сей день остается разработка продуктов питания из растительного сырья, богатого незаменимыми нутриентами. При этом важно использование местных сырьевых источников, имеющих богатый витаминно-минеральный, аминокислотный и жирнокислотный состав наряду с невысокой стоимостью.

Перспективным сырьем с этой точки зрения является амарант. Зерно амаранта превосходит многие традиционные злаковые культуры по содержанию белка (от 16 до 19 $\%$ ), незаменимых аминокислот, витаминов, макро- и микроэлементов, биологически активных веществ, жира (от 6 до $10 \%$ ) и ценного лечебного соединения - сквалена (от 5 до 8 60
\%). В семенах этого растения содержится масло, которое характеризуется наличием около $77 \%$ ненасыщенных жирных кислот, витамина Е в редкой форме токотриена.

Много в амарантовом масле и фосфролипидов, среди которых преобладает лецитин [1].

Ряд исследований в нашей стране и за рубежом показывает перспективы использования этой культуры при производстве хлебобулочных, молочных, мясных и других продукTOВ $[1,2]$.

Отруби амаранта в свою очередь содержат практически в два раза больше клетчатки, чем пшеничные отруби. Кроме того, они богаты белком, витаминами и минеральными веществами [3].

В связи с вышесказанным нами была исследована возможность использования отрубей амаранта в рецептуре густых зерновых киселей.

В качестве клейстерообразующей добавки взамен традиционного картофельного крахмала была выбрана ячменная мука. В качестве рецептурных компонентов для изготовления густого киселя с ячменной мукой использовались:

- какао-порошок по ГОСТ 108-2014;

- ванилин (ГОСТ 16599-71); 
- молоко питьевое пастеризованное по ГОСТ 31450-2013;

- сахар белый кристаллический, по качеству соответствующий требованиям ГОСТ 33222-2015.

На начальном этапе был проведен сравнительный анализ ячменной муки трех производителей, представленных на рынке г. Барнаула. Для этого в образцах была определена зольность, кислотность, крупность стандартными методиками и исследована на капиллярном вискозиметре кинематическая вязкость клейстеров из сырой муки и из муки, подвергнутой термической обработке при 110 ${ }^{\circ} \mathrm{C}$ в течение 20 минут $[4,5]$.

Полученные результаты крупности и кислотности приведены в таблице 1.

Таблица 1 - Крупность и кислотность ячменной муки разных производителей

\begin{tabular}{|l|c|c|c|}
\hline Показатель & $\begin{array}{c}\text { ООО } \\
\text { «Злаки } \\
\text { Сибири» }\end{array}$ & $\begin{array}{c}\text { ООО } \\
\text { «Гарнец» }\end{array}$ & $\begin{array}{c}\text { ПК } \\
\text { «Образ } \\
\text { жизни» }\end{array}$ \\
\hline $\begin{array}{l}\text { Крупность } \\
\text { помола, \% } \\
\begin{array}{l}\text { остаток на } \\
\text { сите №27ш } \\
\text { проход сита } \\
\text { №38ш }\end{array}\end{array}$ & 22,2 & 15,1 & 12,5 \\
\hline $\begin{array}{l}\text { Кислотность, } \\
\text { град }\end{array}$ & 3,0 & 31,5 & 76,4 \\
\hline
\end{tabular}

Отраженные в таблице данные показывают, что кислотность муки разных производителей имеет практически одинаковые значения, не превышающие предельных, что говорит о том, что окислительной порчи жиров ни в одной муке не происходит, а значит, в этом плане мука является доброкачественной. Также можно судить о том, что количество органических и водорастворимых аминокислот в муке разных производителей приблизительно одинаково.

Крупность является важной характеристикой размера частиц муки. Для киселей крупность муки имеет решающее значение, поскольку чем мельче размер частиц, тем интенсивнее будет идти процесс их набухания, что связано с увеличением площади взаимодействия этих частиц с водой. Кроме того, тонкий помол муки создает более однородную консистенцию готового блюда и обеспечивает его лучшую усвояемость.

Из таблицы видно, что крупнее всего частицы ячменной муки, произведенной ООО «Злаки Сибири». Тогда как наиболее тонкий помол выявлен у муки производственной компании «Образ жизни».
Минеральные вещества не обладают энергетической ценностью, как белки, жиры и углеводы. Однако без них жизнь человека невозможна. Минеральные вещества выполняют пластическую функцию в процессе жизнедеятельности человека, но особенно велика их роль в построении костной ткани, где преобладают такие элементы, как фосфор и кальций. Многие ферментативные процессы в организме невозможны без участия тех или иных веществ.

Внутри основных составных частей зерна распределение химических веществ неодинаково. Так, в эндосперме большее содержание белка, липидов, витаминов, а минеральных веществ - в наружных, примыкающих к алейроновому слою частях.

Основным показателем, характеризующим количество минеральных веществ в муке, является зольность. В то же время по зольности можно судить и о количестве отрубянистых частиц. В связи с чем было исследовано содержание золы в ячменной муке разных производителей. Результаты исследования приведены на рисунке 1.

Диаграмма показывает, что наибольшее содержание минеральных веществ имеет ячменная мука ПК «Образ жизни». Несмотря на наиболее мелкий помол, можно предположить, что эта мука содержит больше пищевых волокон, чем аналоги, представленные на рынке г. Барнаула.

Главным показателем, характеризующим кисель, является его консистенция, обусловленная входящим в рецептуру крахмалом. Наличие в ячменной муке крахмала дает возможность использовать ее в качестве альтернативы картофельному и кукурузному крахмалу в составе киселей.

Для оценки консистенции применяют различные методы, один из которых - определение кинематической вязкости. В свою очередь, на вязкость мучного клейстера влияет не только количество и строение крахмала в сырье, но и гидрофильные свойства белков, которые могут отличаться в зависимости от технологии производства муки и от ее состава.

Под влиянием температуры может происходить разрыв большого числа связей, стабилизирующих пространственную структуру белковой молекулы. Упорядоченная, уникальная для каждого белка конформация пептидной цепи при этом нарушается, и белковая молекула целиком или большая ее часть принимает форму беспорядочного клубка - происходит его денатурация [6]. В то же время термическое воздействие на крахмал прояв- 
ляется в его гидролизе с образованием водорастворимых декстринов и сахаров.

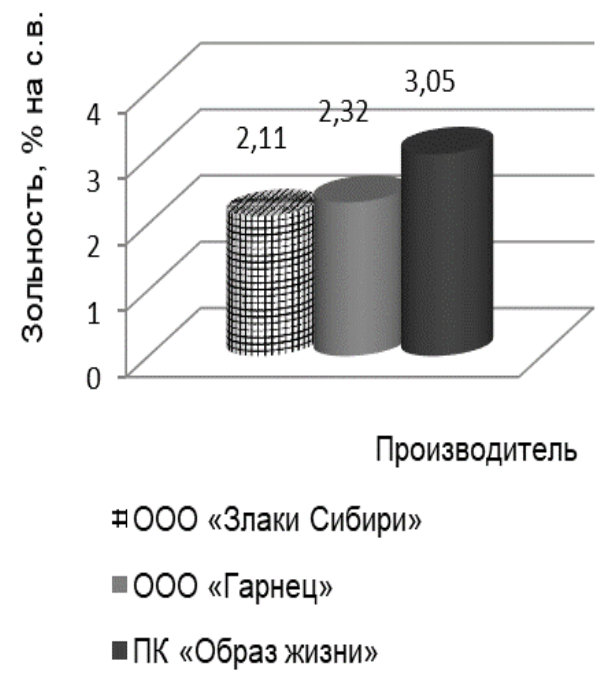

Рисунок 1 - Зольность ячменной муки разных производителей

В этой связи было проведено исследование кинематической вязкости клейстеров сырой ячменной муки разных производителей и муки, подвергнутой термической обработке при температуре 110 $\mathrm{C}$ в течение 20 минут [4, 5].

Для определения кинематической вязкости готовили 3\%-ю суспензию муки в воде, при постоянном перемешивании доводили суспензию до кипения и варили в течение заданного времени. Полученный клейстер охлаждали до $20^{\circ} \mathrm{C}$ без перемешивания. Полученные образцы исследовали на капиллярном вискозиметре ВПЖ-4. Результаты определения представлены на рисунке 2.

Из рисунка видно, что наименьшую вязкость имеет клейстер, приготовленный из ячменной муки ООО «Злаки Сибири». Тогда как вязкость клейстера образца ПК «Образ жиз-

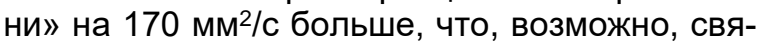
зано с меньшим размером частиц данной муки. Мука, выработанная ООО «Гарнец», дает клейстер с вязкостью $180 \mathrm{~mm}^{2} / \mathrm{c}$ и занимает среднее положение среди представленных образцов. При этом термическая обработка при $110{ }^{\circ} \mathrm{C}$ в течение 20 минут приводит к увеличению вязкости во всех образцах, что связано с изменениями в крахмале и белке.

Таким образом, в результате комплексного анализа полученных данных, с уверенностью можно сказать о том, что наиболее подходящей для использования в составе киселей является мука с наименьшим размером частиц, но вместе с тем с наибольшим количеством пищевых волокон и минераль- ных веществ. При этом установлено, что муку необходимо предварительно подвергать термической обработке при $110^{\circ} \mathrm{C}$ в течение 20 минут.

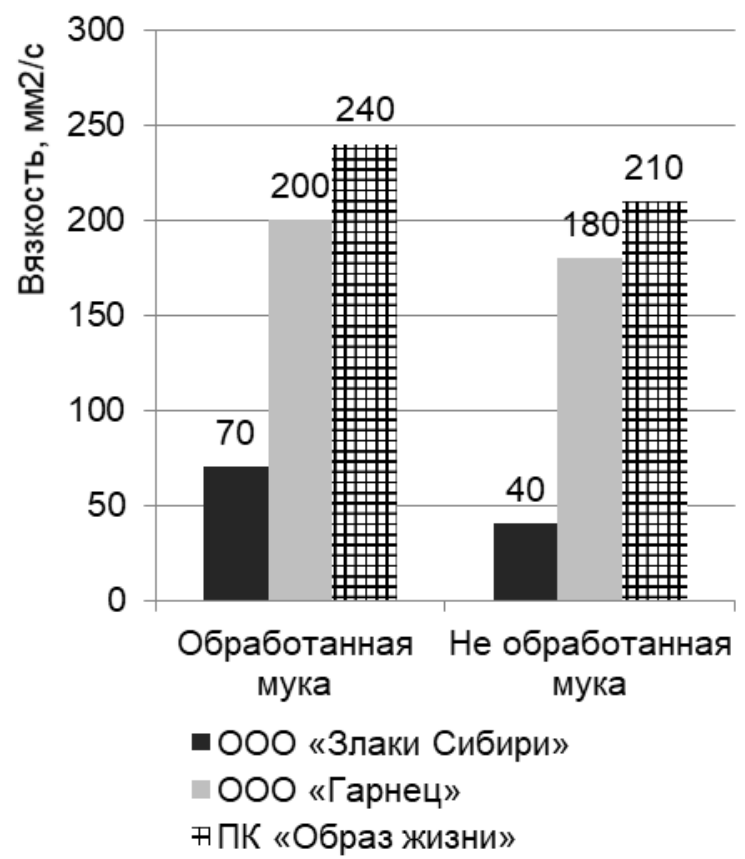

Рисунок 2 - Вязкость клейстеров из обработанной при $110{ }^{\circ} \mathrm{C}$ в течение 20 мин и не обработанной муки разных производителей

Затем экспериментальным путем была подобрана дозировка обработанной ячменной муки для достижения структуры, аналогичной структуре густого молочного киселя из сборника рецептур. Для улучшения органолептических показателей в ячменный кисель добавляли какао-порошок, а для повышения пищевой ценности - отруби амаранта.

Для определения оптимальной дозировки отрубей амаранта в готовом киселе были взяты навески массой 1, 2, 3, 4 и 5 г на 100 г готового продукта.

Далее была проведена органолептическая оценка готовых киселей по четырем характеристикам (вкус, внешний вид, запах и консистенция).

В наименьшей дозировке отруби амаранта не давали постороннего привкуса и запаха. Консистенция продукта также оставалась неизменной. Увеличение массы отрубей более 4 г привело к появлению слишком явного постороннего привкуса, запаха и ухудшило консистенцию продукта, что связано с рыхлостью отрубей и разрушением структуры клейстера.

Несмотря на хорошие органолептические характеристики киселей с 1, 2, и 3 г отрубей ПОЛЗУНОВСКИЙ ВЕСТНИК № 22018 
амаранта, целью исследований было получить наиболее полезный продукт, в связи с чем была выбрана дозировка 4 г.

На следующем этапе был проведен сравнительный анализ пищевой ценности традиционного киселя из сборника рецептур и ячменного киселя с отрубями амаранта, результаты которого представлены в таблице 2.

Таблица 2 - Пищевая ценность густого ячменного киселя с отрубями амаранта

\begin{tabular}{|c|c|c|c|c|c|}
\hline \multirow[t]{3}{*}{ Пищевые вещества } & \multirow{3}{*}{$\begin{array}{c}\text { Средняя су- } \\
\text { точная по- } \\
\text { требность } \\
\text { [7] }\end{array}$} & \multicolumn{2}{|c|}{$\begin{array}{c}\text { Фактические данные на } \\
100 \text { г киселя }\end{array}$} & \multicolumn{2}{|c|}{$\begin{array}{c}\text { Процент удовлетворения } \\
\text { суточной потребности }\end{array}$} \\
\hline & & \multicolumn{4}{|c|}{ Вид киселя } \\
\hline & & Ячменный & $\begin{array}{c}\text { Традицион- } \\
\text { ный }\end{array}$ & Ячменный & $\begin{array}{c}\text { Традицион- } \\
\text { ный }\end{array}$ \\
\hline Белки, г & 81,8 & 6,9 & 2,6 & 8 & 3 \\
\hline Жиры, г & 96,5 & 4,4 & 2,3 & 5 & 2 \\
\hline Углеводы, г & 421,5 & 18,8 & 23,1 & 5 & 6 \\
\hline Пищевые волокна, г & 20,0 & 6,2 & 0,1 & 31 & 1 \\
\hline Витамин С, мг & 90,00 & 1,17 & 1,17 & 1 & 1 \\
\hline Витамин В 1 , мг & 1,50 & 0,46 & 0,04 & 31 & 3 \\
\hline Витамин $\mathrm{B}_{2}, \mathrm{мг}$ & 1,80 & 0,18 & 0,07 & 10 & 4 \\
\hline$\beta$-каротин, мг & 5,00 & 0,13 & 0,09 & 3 & 2 \\
\hline Витамин Е, мг & 4,00 & 0,28 & 0,00 & 7 & 0 \\
\hline Кальций, мг & 1000,00 & 152,23 & 111,24 & 15 & 11 \\
\hline Фосфор, мг & 800,00 & 220,69 & 86,78 & 28 & 11 \\
\hline Магний, мг & 400,00 & 85,07 & 12,60 & 21 & 3 \\
\hline Калий, мг & 2500,00 & 361,40 & 132,77 & 14 & 5 \\
\hline Натрий, мг & 1300,00 & 57,90 & 45,53 & 4,5 & 4 \\
\hline Железо, мг & 14,00 & 8,22 & 0,11 & 59 & 1 \\
\hline $\begin{array}{l}\text { Энергетическая } \\
\text { ценность, ккал }\end{array}$ & 2500 & 323 & 312 & 13 & 12 \\
\hline
\end{tabular}

При этом содержание какао-порошка, сахара, ванилина и молока в обоих образцах было одинаково, а вместо картофельного крахмала использовалась обработанная ячменная мука в том же количестве и 4 \% отрубей амаранта к массе готового блюда.

Как показывают данные, приведенные в таблице, благодаря внесению в кисель ячменной муки и отрубей амаранта значительно повышается содержание пищевых волокон. Так, порция ячменного киселя удовлетворяет суточную потребность в пищевых волокнах на $31 \%$, тогда как традиционный кисель на крахмале практически не имеет в своем составе пищевых волокон. Кроме того, значительно возрастает содержание минеральных веществ. Благодаря внесению отрубей амаранта, богатого железом, содержание этого микроэлемента возрастает на 58 \%. В семь раз увеличивается содержание магния и почти в три раза фосфора. Наличие в ячменной муке и отрубях амаранта витаминов группы В приводит к тому, что порция готового киселя с этим сырьем удовлетворяет суточную потребность в витаминах: $\mathrm{B}_{1}$ - на $31 \%$, $\mathrm{B}_{2}$ - на $10 \%$.

ПОЛЗУНОВСКИЙ ВЕСТНИК № 22018
Таким образом, опираясь на ГОСТ Р 55577-2013 и подтвердив экспериментальным путем полученные расчётные данные, можно с уверенностью назвать разработанное блюдо функциональным. При этом в информации о пищевой ценности возможно указывать, что продукт имеет высокое содержание пищевых волокон, витамина $\mathrm{B}_{1}$ и железа. Кроме того, является источником магния, фосфора и кальция. Информация также может содержать надписи: «Способствует усилению перистальтики кишечника», «Способствует нормализации энергетического обмена», «Способствует поддержанию нормального состояния костей», «Способствует нормализации транспорта кислорода и синтеза гемоглобина и миоглобина в организме» $[8,9,10]$.

Результаты получены в рамках выполнения государственного задания $15.5401 .2017 / 7.8$

\section{СПИСОК ЛИТЕРАТУРЫ}

1. Мелешкина, Е. Амарантовая мука в хлебопечении / Е. Мелешкина, А. Меньшенин, А. Мед- 
ведев // Наука. Техника. Производство. - 2005. № 10. - C. 43-44.

2. Мартиросян, В. В. Применение нетрадиционного сырья в технологии хлеба / В. В. Мартиросян // Известия вузов. Пищевая технология. 2008. - № 2 - 3. - С. 38-39.

3. Смирнов, С. О. Разработка технологии разделения зерна амаранта на анатомические части и получения из них нативных продуктов: дис. ... канд. техн. наук: 05.18.01 / С. О. Смирнов. - М., 2006. -215 c.

4. Пат. 2414147 C1 Рос. Федерация, МПК ${ }^{7}$ A23L 1/212. Смесь для получения киселя / Мелёшкина Л. Е., Снегирева А. В.; заявитель и патентообладатель Алт. гос. техн. ун-т им. И.И. Ползунова. - № 2009142343/13; заявл 17.11.2009; опубл. 20.03.2011.

5. Снегирева, А. В. Способ подготовки ячменной муки к использованию в составе пищевых концентратов напитков / А. В. Снегирева, Л. Е. Мелёшкина // Ползуновский вестник. - 2010. - № 3. C. 261-264.

6. Биохимия / под ред. В. Г. Щербакова. - 3-е изд., испр. и доп. - СПб. : ГИОДР, 2005. - 472 с.

7. Нормы фризиологических потребностей в энергии и пищевых веществах для различных групп населения Российской федерации: методи- ческие рекомендации: МР 2.3.1.2432-08 / ГУИ Институт питания РАМН. - М., -39 с.

8. ГОСТ Р 52349-2005 Продукты пищевые. Продукты пищевые функциональные. Термины и определения. - Введ. 2006-07-01. - Режим доступа: $\quad$ http://astulib.secna.ru/reader/pravila\%20 opisania.pdf

9. ГОСТ Р 55577-2013 Продукты пищевые функциональные. Информация об отличительных признаках и эффрективности. - Введ. 2015-01-01. Режим доступа: http://docs.cntd.ru/ document/1200107585

10. ГОСТ Р 54059-2010 Продукты пищевые функциональные. Ингредиенты пищевые функциональные. Классификация и общие требования. Введ. 2012-01-01. - Режим доступа: http://docs.cntd.ru/document/1200085998

Снегирева Анна Владимировна, к.т.н., дочент кафедры «Технологии продуктов питания» АлтГТУ, тел. (3852) -29-07-54, sne.anna@mail.ru.

Мелёшкина Лариса Егоровна, к.т.н., доцент кафедры «Технологии продуктов питания» АлтГТУ, тел. (3852) -29-07-54. 